\title{
Identification of catchment functional units by time series of thermal remote sensing images
}

\author{
B. Müller ${ }^{1,2}$, M. Bernhardt ${ }^{2}$, and K. Schulz ${ }^{1}$ \\ ${ }^{1}$ Institute of Water Management, Hydrology and Hydraulic Engineering, University of Natural \\ Resources and Life Sciences, Vienna, Austria \\ ${ }^{2}$ Department of Geography, Ludwig-Maximilians-Universität, Munich, Germany \\ Correspondence to: B. Müller (b.mueller@iggf.geo.uni-muenchen.de)
}

Received: 26 May 2014 - Published in Hydrol. Earth Syst. Sci. Discuss.: 27 June 2014

Revised: 1 November 2014 - Accepted: 3 November 2014 - Published: 19 December 2014

\begin{abstract}
The identification of catchment functional behavior with regards to water and energy balance is an important step during the parameterization of land surface models.

An approach based on time series of thermal infrared (TIR) data from remote sensing is developed and investigated to identify land surface functioning as is represented in the temporal dynamics of land surface temperature (LST).

For the mesoscale Attert catchment in midwestern Luxembourg, a time series of 28 TIR images from ASTER (Advanced Spaceborne Thermal Emission and Reflection Radiometer) was extracted and analyzed, applying a novel process chain.

First, the application of mathematical-statistical pattern analysis techniques demonstrated a strong degree of pattern persistency in the data. Dominant LST patterns over a period of 12 years were then extracted by a principal component analysis. Component values of the two most dominant components could be related for each land surface pixel to land use data and geology, respectively. The application of a data condensation technique ("binary words") extracting distinct differences in the LST dynamics allowed the separation into landscape units that show similar behavior under radiationdriven conditions.

It is further outlined that both information component values from principal component analysis (PCA), as well as the functional units from the binary words classification, will highly improve the conceptualization and parameterization of land surface models and the planning of observational networks within a catchment.
\end{abstract}

\section{Introduction}

Resolving the spatial variability of hydrological processes at the land surface within spatially explicit physical-based models is, nowadays, still a very time-consuming and expensive task that is not applicable for operational purposes. Therefore, a large variety of hydrological models is based on the delineation of spatially distributed hydrological functional units that are assumed to behave or function in a similar way for some given initial or boundary condition (Flügel, 1995a). They are often referred to as hydrological response units (HRUs) and represent classes of landscape entities that share common climate, land use and underlying pedo-topogeological characteristics.

In this way, the number of computational units is significantly reduced, thus facilitating an efficient parameterization and calculation process. Examples of hydrological model systems following the HRU concept are the Soil Water Assessment Tool (SWAT) (Arnold et al., 1998; Srinivasan et al., 1998), the Cold Regions Hydrological Model (CRHM) (Pomeroy et al., 2007) or the Precipitation-Runoff Modeling System/Modular Modeling System (PRMS/MMS) (Flügel, 1995b), amongst many others. While the HRU concept has been criticized in the past for, e.g., often neglecting the lateral exchange processes that are driven by inter-unit gradients (Neumann et al., 2010), Zehe et al. (2014) have recently extended the original HRU concept by "postulating a hierarchy of functional units, lead topologies and elementary functional units compiling the main catchment functions in a given hydrological setting by spatially organized interactions at and across different scales". 
In any of these concepts, the delineation of HRUs or functional units is mainly based on information that is directly related to land and subsurface characteristics that are well known to have some control on a wide range of hydrological processes (such as geology on soil type, soil texture and therefore hydraulic conductivity, or slope on the hydraulic gradient), but that do not represent directly internal states or (water) fluxes.

In order to characterize this spatial (hydrological) functioning of the landscape at larger scales, it would be beneficial to have relevant information at hand that will be available routinely (and also at locations that are ungauged) via remote sensing. Typical data parameters are digital elevation models (DEMs) from radar missions (Farr et al., 2007; NASA, 2009), land use-land cover data (EEA, 2014; EPA, 2007), as well as soil parameters (Lagacherie et al., 2012; Mulder et al., 2011; Summers et al., 2011; Ladoni et al., 2010; Kheir et al., 2010; Serbin et al., 2009a, b; Eldeiry et al., 2010) from sensors within the visible and near-infrared spectrum.

Other important spatial information that can be obtained from remote sensing is land surface temperature (LST). It results from a complex balance and interaction of incoming and outgoing short- and longwave radiation, as well as sensible, latent and ground heat fluxes (Moran, 2004). Therefore, LST is highly controlled by geographic location, atmospheric state, soil (moisture) and vegetation conditions. The monitoring of LST at the catchment scale via thermal infrared (TIR) remote sensing from, e.g., Landsat (spatial resolution: 4 and 5-120 $\mathrm{m}, 7-60 \mathrm{~m}$ and $8-100 \mathrm{~m}$ ), ASTER $(90 \mathrm{~m})$ or MODIS $(1 \mathrm{~km})$ has been used in the past primarily to derive sensible and latent heat fluxes (Bolle et al., 1993; Farah and Bastiaanssen, 2001). Given the control of latent heat fluxes by the available water content (and therefore by hydraulic properties of the soil, the location within the catchment - Beven and Kirkby, 1979 - and the phenological and physiological states of the plants - Taiz and Zeiger, 2010), TIR data have also been applied to estimate soil hydraulic properties, bulk density or volumetric water content using complex soil-vegetation-atmosphere transfer (SVAT) schemes (e.g., Steenpass et al., 2010).

In this way, LST can be seen as a complex ecosystem state variable that aggregates a variety of (micro-)meteorological and hydrological processes, as well as land surface characteristics at each individual pixel in a catchment. The spatiotemporal dynamics of LST are therefore important information in order to distinguish spatially different functional behavior of the landscape.

In the following, the dynamic patterns of LST are investigated for the $288 \mathrm{~km}^{2}$ Attert catchment in Luxembourg using 28 ASTER (Advanced Spaceborne Thermal Emission and Reflection Radiometer) TIR remote sensing images over a time period of 12 years. The persistency of the LST pattern time series is analyzed in two different novel ways deriving summary statistics of the correlation of shifted windows across the original or recoded images and/or time steps (over- all pattern persistency and pattern dynamics persistency). The following principal component analysis (PCA) of the LST pattern time series allows the identification of dominant independent patterns within the time series, ranked by the ability to explain the temporal variation in the LST time series. Relating the dominant principal components to available land surface characteristics will allow one to extract the most important controls of LST variation in the catchment under study. Finally, a novel scheme is suggested to group pixels or sites into a manageable number of functional units based on their "behavior" that is expressed in a binarized form of LST dynamics for a representative subset of images.

The rest of the paper is organized as follows: Sect. 2 will introduce the test site, the data used and the preprocessing steps necessary. Section 3 will describe the methods applied, as well as results in a stepwise approach. Finally, Sect. 4 summarizes and discusses main findings and gives an outlook to future research.

\section{Data and preprocessing}

\subsection{Test site}

The study area is the Attert catchment, located in midwestern Luxembourg and partially in Belgium (see Fig. 1). It is the main test site of the German DFG research project CAOS ("Catchments as Organised Systems"; CAOS, 2014) with a total catchment area of $288 \mathrm{~km}^{2}$ at the gauge in Bissen. The undulating landscape with a mean slope of $8.4 \%$ spans between $222 \mathrm{~m}$ and $535 \mathrm{~m}$ a.s.l. The northern slopes are geologically defined by schists from the Ardennes massif, while the mainly southern slopes arise on sandstones from the Paris basin Mesozoic deposits (compare Fig. 9). Soils vary between sand and silty clay loam. The land cover of the catchment is predominantly cultivated; $4.8 \%$ of the area is accounted for settlements and rather impermeable surface, $65.4 \%$ for agricultural used land, located predominantly on the knolls, and $29.7 \%$ for forests, located predominantly in the V-shaped valleys (compare Fig. 9). Climate is characterized by mean monthly temperatures between $18^{\circ} \mathrm{C}$ in July and $0{ }^{\circ} \mathrm{C}$ in January (1971-2000). The mean annual precipitation is $850 \mathrm{~mm}$ and the mean annual actual evapotranspiration is $570 \mathrm{~mm}$ (1971-2000), resulting in a pluvial oceanic regime with low flows within July to September due to high summer evapotranspiration, and high flows mainly from December to February.

\subsection{Spatial data}

The multispectral imaging system ASTER on board the TERRA satellite, launched in December 1999, orbits on a near circular, sun-synchronous path with a repeat cycle of 4-16 days. The ASTER instrument consists of three sensors (VNIR - visible-near infrared: 0.52-0.86 $\mu \mathrm{m}$; SWIR - shortwave infrared: $1.6-2.43 \mu \mathrm{m}$; TIR - thermal infrared: 8.125 


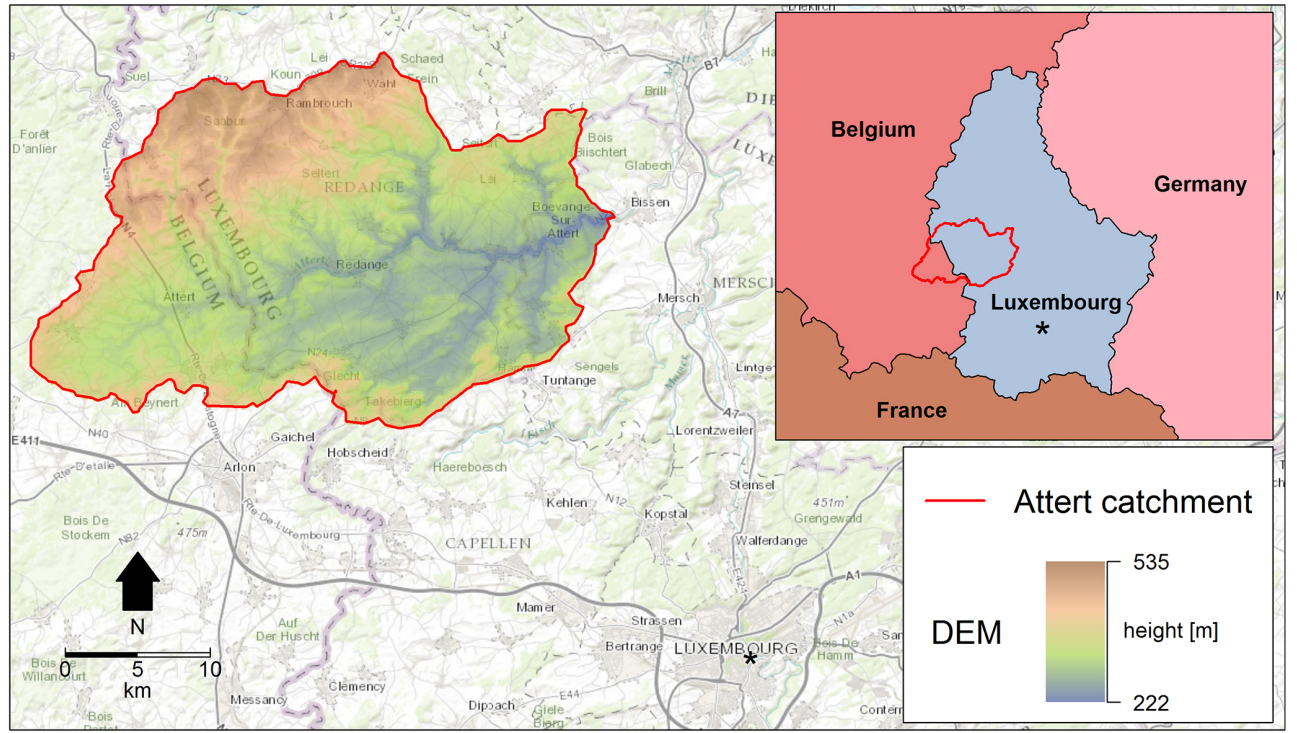

Figure 1. The location of the Attert catchment and its elevation. Catchment boundaries are given for the Bissen gauge, Luxembourg.

$11.65 \mu \mathrm{m}$ ) with four, six and five bands, respectively (Fujisada, 1995). For this study, only the Level 1A (raw) TIR data band 13 , within $10.25-10.95 \mu \mathrm{m}$, with a spatial resolution of $90 \mathrm{~m}$, are used. This band is chosen due to the lowest absorption of the atmosphere and therefore least altered thermal signals (compare Elder and Strong, 1953). The local overpass time is around 11.40 a.m. CET. Between January 2001 and June 2012, a total of 28 snow-free images (see Fig. 2, after preprocessing), with a maximum cloud cover of $15 \%$, were extracted. In addition, Corine land cover (EEA, 1995) updated from 2006 (Fig. 9, upper right), and a geological map based on dominant rock formations (SGL, 2003) (Fig. 9, lower right), are used for further analysis.

\subsection{Preprocessing}

The used Level 1A (raw) TIR data product lacks a proper georeferencing. This was applied manually with 60 to 70 ground control points (depending on the cloud cover), achieving a mean accuracy of $40 \mathrm{~m}$ within the Attert catchment. In this transformation step, the spatial resolution of the images was adjusted from $90 \mathrm{~m}$ to $15 \mathrm{~m}$ by assigning the nearest neighbor values. The geo-positioned images were then converted from unprocessed digital numbers to top-ofatmosphere (TOA) temperatures $\left(T_{\mathrm{TOA}}\right)$ with standard parameters, as given by CESSLU (2009). Sensor decay was not taken into account as decay errors due to spatially homogeneous and heterogeneous degradation of the sensor (sensitivity) are a magnitude smaller than measurement accuracy, according to Hook et al. (2007). Merely homogenous atmospheric conditions throughout the catchment were assumed for each single time step and, as our focus is on statistical pattern analysis rather than absolute LST values, atmospheric correction was omitted here and $T_{\mathrm{TOA}}$ is used in the following. Additionally, calculating cloud masks was omitted as heavy fragmentation of the full time series would occur if masks were applied for even small clouds in every affected image and cumulatively applied for the full series. In the further statistical analysis, the distortion of results due to clouds is negligibly small, as occurring clouds are neither repeating in certain areas nor of large spatial extent per image. The time series of LST for individual pixels in the data set hence include one outlier due to clouds at most. This does not heavily influence further calculations on the full pattern. For simplification reasons, the calculated data are further referred to as LST time series.

\section{Methods and analysis}

The general objective was to explore the relevance of the spatio-temporal dynamics of land surface temperature as a determinant of the functional behavior of the water and energy balance of a landscape unit in a given watershed. In the first part of the analysis, the persistency of the LST patterns, both in a temporal as well a spatio-temporal context, was explored to analyze the existence of spatially and temporally consistent patterns. The second part will analyze the most dominant structures and patterns in the landscape that can be extracted from LST time series using PCA and will also investigate the relationship between dominant structures from LST-PCA and other landscape characteristics. In the third part, landscape functional units will then be classified based on the PCA results. 

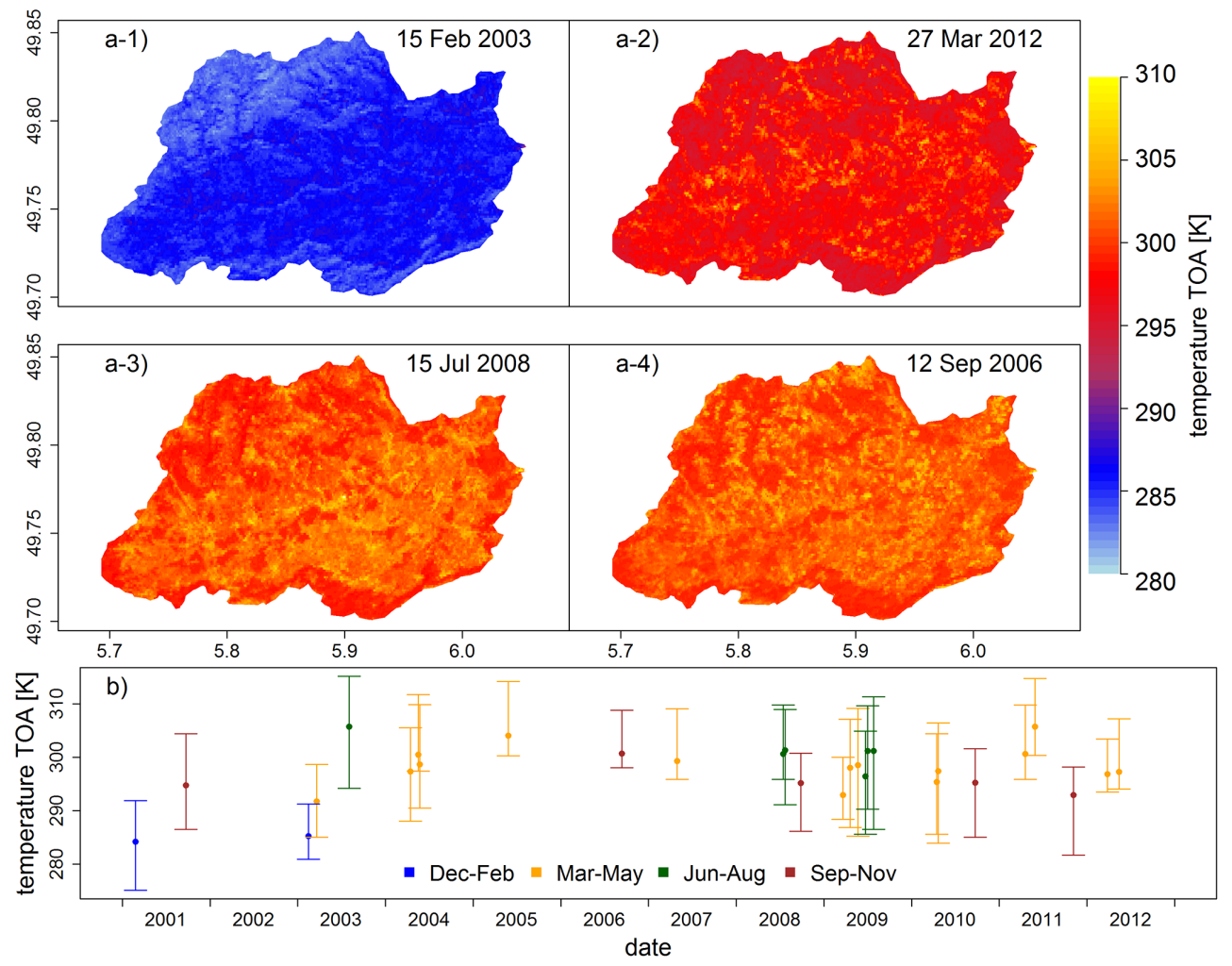

Figure 2. (a) Examples of single band top-of-atmosphere (TOA) temperature time series covering winter (1), spring (2), summer (3) and autumn (4). (b) Basic temporal and statistical information (mean, ranges) of the image time series.

\subsection{Overall pattern persistency}

The first aim was to demonstrate that LST patterns, although changing throughout time, persist to a certain degree and hence provide information on the local organization of land surface energy and water balance within the full catchment. The absence of persistency would imply competing patterns within the time series and hence sever changes within the controlling features or even oscillating states within the time series. A further investigation of the timing of the pattern changes and appropriate splitting of the time series would be imminent to a comprehensive pattern analysis. In such a case, the following steps need to be executed for the separated data sets. In order to analyze the overall pattern persistency within the time series while retaining spatial patterns, a procedure similar to that used for "co-referencing" different ASTER TIR bands is used (Hirschmüller et al., 2002). The correlation of shifted windows within two images indicates whether there is a clear shift within the overall pattern in any spatial direction, or if "blurring" occurs and persistency is then absent. Therefore, the square window $w$ of defined size (e.g., $3 \times 3$ pixel $(\mathrm{px})$ ) around the $P_{\mathrm{c}}$ pixel of the image $I_{1}$ (time step 1) is selected and the correlation coefficient is calculated for the same window (e.g., from $3^{2}=9$ values) in the image $I_{2}$ at time step 2 (Fig. 3a). The window within the second image is now shifted within defined maximum ranges $r_{1}$ and $r_{2}$ (e.g., $r_{1}=[-3,+3]$ in $\mathrm{N}-\mathrm{S}$ direction, $r_{2}=[-3,+3]$ in $\mathrm{E}-\mathrm{W}$ direction; Fig. 3b), and correlation coefficients are assigned for any shifted position $(\mathrm{d} x, \mathrm{~d} y)$ of $P_{\mathrm{c}}$ and they produce square fields of correlation coefficients (e.g., $7 \times 7 \mathrm{px}$; Fig. 3c).

The persistency of the patterns in the LST data within two time steps is then assessed by calculating average correlation coefficient fields for a sample of well distributed central pixels, depending on the ratio of window and shift size to image size (to reduce the effort of calculating a shift for the whole image). The overall persistency of the patterns is the average of the correlation coefficients for all combinations of patterns within the time series $(28 \times(28-1)=756)$. In case the maximum correlation coefficient is within a shift of $(0,0)$ and the decrease of the correlation coefficients is large towards bigger shifts (= no blurring of a single peak), the persistency of the overall pattern over time is considered as high.

For our LST time series, the observed overall patterns are stationary persistent in general. By calculating the mean correlation coefficient within the full time series data set and a range of shifts of $[-50,+50]$ in both directions (Fig. 4), it is shown that the peak correlation value is within a shift of $(4,1)$ px and hence within the range of the resolution of one original ASTER pixel $(4 \times 15 \mathrm{~m}=60 \mathrm{~m})$. Also, the overall positioning of temperature values within the patterns is correlated 

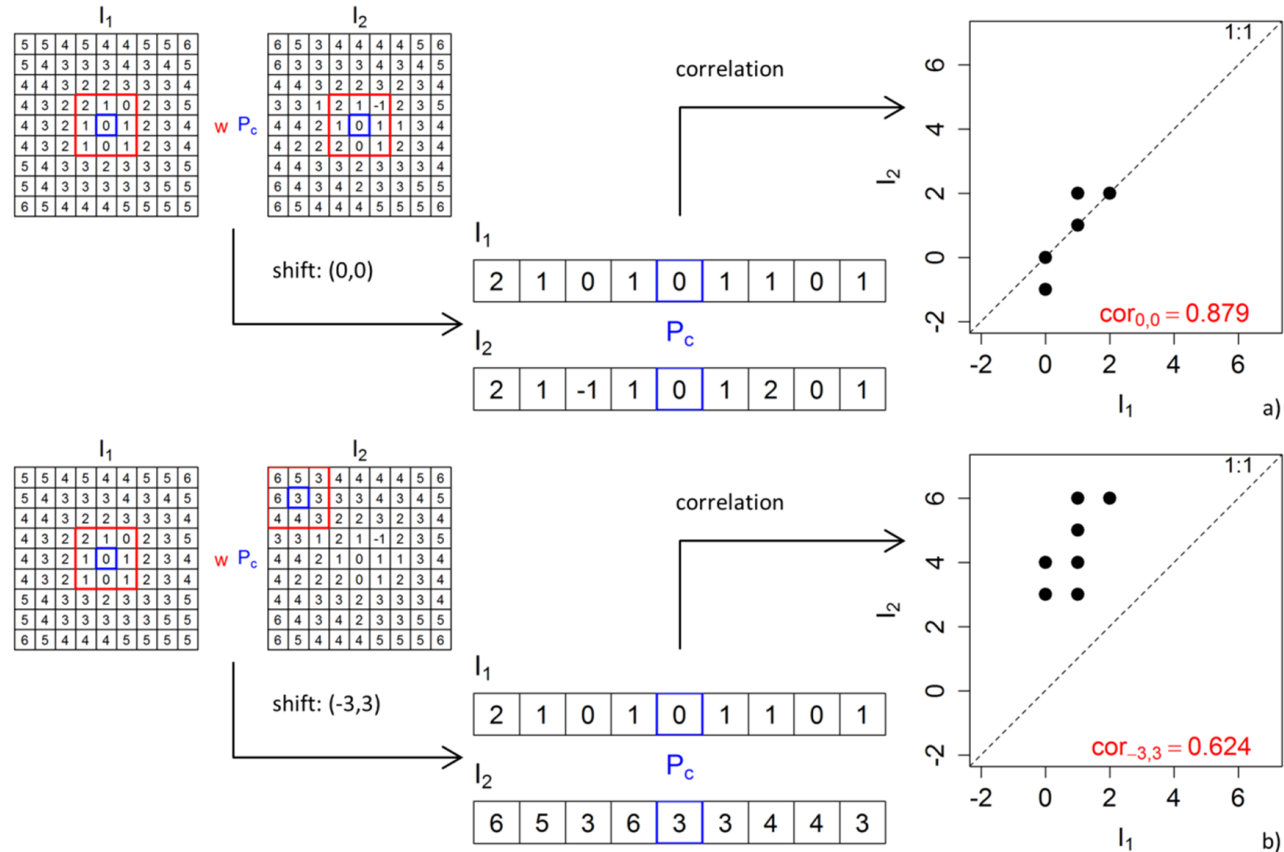

\begin{tabular}{|c|c|c|c|c|c|c|c|c|}
\hline \multicolumn{9}{|c|}{ e.g. $\mathrm{I}_{2}$} \\
\hline 6 & 5 & 3 & 4 & 4 & 4 & 4 & 5 & 6 \\
\hline 6 & 3 & 3 & 3 & 3 & 4 & 3 & 4 & \\
\hline 4 & 4 & 3 & 2 & 2 & 3 & 2 & 3 & \\
\hline 3 & 3 & 1 & 2 & 1 & -1 & $?$ & 3 & \\
\hline 4 & 34 & 2 & 1 & 0 & 1 & & & \\
\hline 4 & 2 & 2 & 2 & 0 & 1 & 2 & 3 & 4 \\
\hline 4 & 4 & 3 & 3 & 2 & 3 & 3 & 3 & 4 \\
\hline 6 & 4 & 3 & 4 & 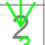 & 3 & 3 & 5 & 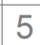 \\
\hline 6 & 5 & 4 & 4 & 4 & 5 & 5 & 5 & \\
\hline
\end{tabular}

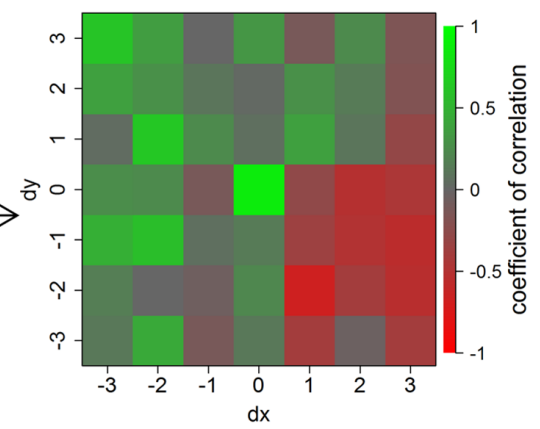

Figure 3. Analysis for the coefficient of correlation for a designed spatial data set. We added small normal distributed noise to the concentric spatial pattern $I_{1}$ to construct $I_{2}$ and show the correlation for an extracted window $w$ (red) around the central pixel $P_{\mathrm{c}}$ (blue) in the same position (a), in different positions (b) and for the whole image $I_{2}$ within the maximum ranges $[-3,+3](\mathbf{c})$.

over times, and, as a first result, it can be derived that temporal trends within the thermal images of the Attert catchment can be considered as "spatially stationary persistent".

\subsection{Pattern dynamics persistency}

In addition to the overall persistency, the temporal dynamics of local LST patterns are investigated using a second type of "moving window" approach. To analyze the spatial relationship of each pixel within its local neighborhood, for each pixel $P_{\mathrm{c}}$ within an image a square window $w$ (the environment) of a defined size (e.g., $3 \times 3 \mathrm{px}$ ) around this central $P_{\mathrm{c}}$ is compared to the value of $P_{\mathrm{c}}$. The environment information (ENV) is summarized to statistical information in the form of percentages of values within the square window that are bigger than, smaller than or equal to the value of $P_{\mathrm{c}}$ (see Fig. 5a for an example analysis of values that are bigger than $P_{\mathrm{c}}$ ).
The variations of the ENV information over time were analyzed for the 28 LST images via the spatial assessment of the coefficient of variation $(|\sigma / \mu|)$ for each of the three setups $(<,=,>$; see example in Fig. $5 \mathrm{c}-\mathrm{d})$. The three spatially distributed coefficients of variation are finally reduced to an average pattern of coefficients of variation by taking the mean value of the three setups (Fig. 5b, right).

Low coefficients of variation over time indicate a very "stable positioning" or rank of that particular pixel within its local environment. An extreme value of zero would mean no change of dynamics over time for the pixel environments; for a value of 1 , the standard deviation is as large as the mean value, suggesting that the persistency of the local pattern is rather low, and values larger than 1 have to be interpreted as non-persistent. In this way, areas of low coefficients indicate stable, persistent local patterns, and distinct varying behavior can be well identified by areas of high coefficients of variation. 


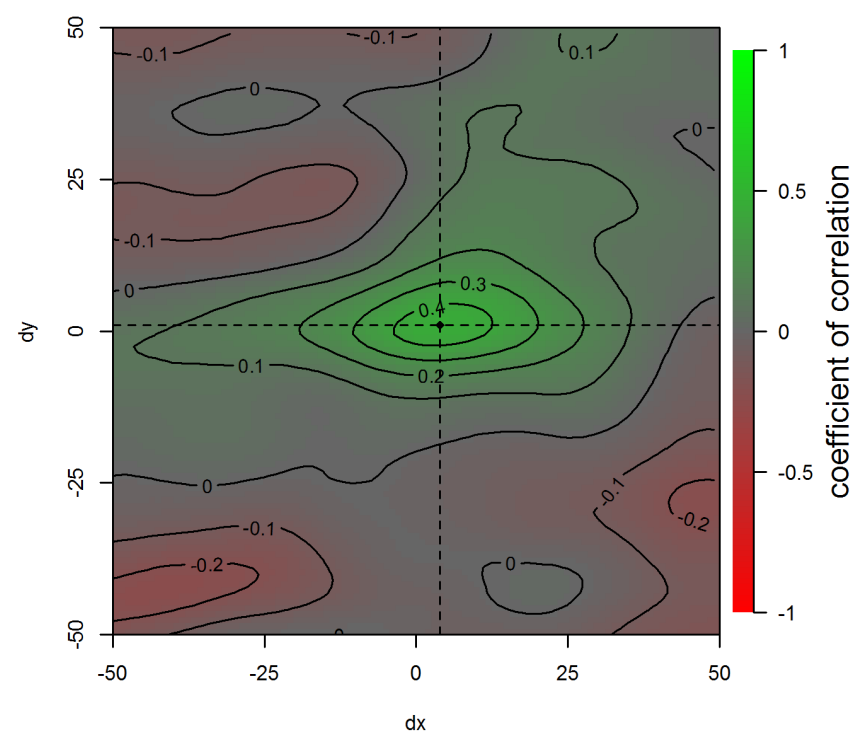

Figure 4. Coefficient of correlation for the LST time series data. The mean coefficient of correlation for all 756 combinations shows a centered behavior (single peak area with maximum correlation of 0.47 ; green) with a low shift $(4,1)$ within a maximum range of $[-50,+50]$ in both $x$ and $y$ direction. The size of the correlation window is $51 \times 51$ px for 5 fixed, non-overlapping positions $(\because$ ) throughout the images.

The analysis of the LST time series using a window size of $15 \times 15 \mathrm{px}=225 \times 225 \mathrm{~m}^{2}$ identifies relatively low coefficients of variation (Fig. 6) with $90 \%$ of the values between 0.19 and $0.55,50 \%$ within the range of 0.27 and 0.42 , and only $0.03 \%$ of the values larger than 1 . This indicates a high local pattern persistency.

Based on both, global and local persistency analysis, relatively stationary patterns at the catchment scale, accompanied by stationary dynamics at the scale of hill slopes throughout the catchment can be expected. The existence of LST pattern persistence also suggests some structured control on LST by some land surface characteristics. In the following section possible controls will be extracted and analyzed.

\subsection{Principle component analysis}

Applying principle component analysis (PCA; for a full mathematical description, see Richards and Jia (2006; chapter 6.1)), or empirical orthogonal functions (EOFs; e.g., Denbo and Allen, 1984; Hamlington et al., 2011; Lorenz, 1956) allows the assessment of independent structures within complex data sets. Because both approaches share a similar methodology, here, PCA is used to determine which spatial factors are controlling patterns of LST within the time series. PCA uses orthogonal transformation to calculate a composition of linearly uncorrelated values of decreasing dominance from possibly correlated monitored variables.
In remote sensing, PCA is often applied to reduce the number of (correlated) variables within classification procedures (see, e.g., Crósta et al., 2003; Moore et al., 2008, for the analysis of multi-spectral, single temporal TIR data to assess different geological structures).

Here, the aim is to transform the observed 28 LST patterns into patterns of virtual and independent principal components. These components represent the most dominant controlling factors for the temporal dynamics of LST pattern in decreasing order. An illustrative example for a PCA application in this context is given in Fig. 7 for artificial data.

The PCA application for the ASTER TIR time series produced 28 independent components as summarized in Table 1. By construction, components with higher (lower) degree show less (more) information and more (less) noise. $61.9 \%$ of the variation is cumulatively expressed via the first five components (third row), while still more than $3 \%$ of the variance are expressed by particular components (second row). In the following, a focus is given to the first five components (Fig. 9).

Figure 8 illustrates a distinct degree of structured heterogeneity for these five components. In principle the patterns of the PCs would allow to classify the catchment or landscape into different functional units that, when using LST images, would strongly reflect the functioning of the landscape related to the water and energy balance under radiation driven conditions. The number of PCs to be considered in such a classification would depend on the overall number of units that should be differentiated (which will strongly depend on computational resources available to explicitly represent within catchment variability), but also on the (cumulative) percentage of explained variance of the PCs, as well as on the distribution or, at least, range of the component values of each individual PC.

However, while this is an important topic related to land surface hydrological modeling, the focus here will be on the relationship of the extracted PCs with other land surface characteristics. Given the controls of LST as discussed in the introduction, it is expected to find some relationship of the first dominant PCs with vegetation, soil, geology, elevation, slope, aspect or others. A comparison of the PCs with available data suggested a strong relationship between PC1 and land use data, as well as PC2 with geological information. These relationships are illustrated in Fig. 9, where maps of PC1 and Corine land cover as well as PC2 and a geological map of the Attert catchment are shown next to each other.

A more detailed analysis is given by Fig. 10, where the distributions of component values of PC1 for the individual Corine land use data (Fig. 10a) and of PC2 for the individual geological classes (Fig. 10b) are plotted separately. The diagrams underpin a strong relationship between both components and suggested land surface characteristics. Concerning land cover, low component values of PC1 are shown for artificial areas, medium values for agricultural areas (arable, pastures, complex cultivation and agricultural/natural) and high 


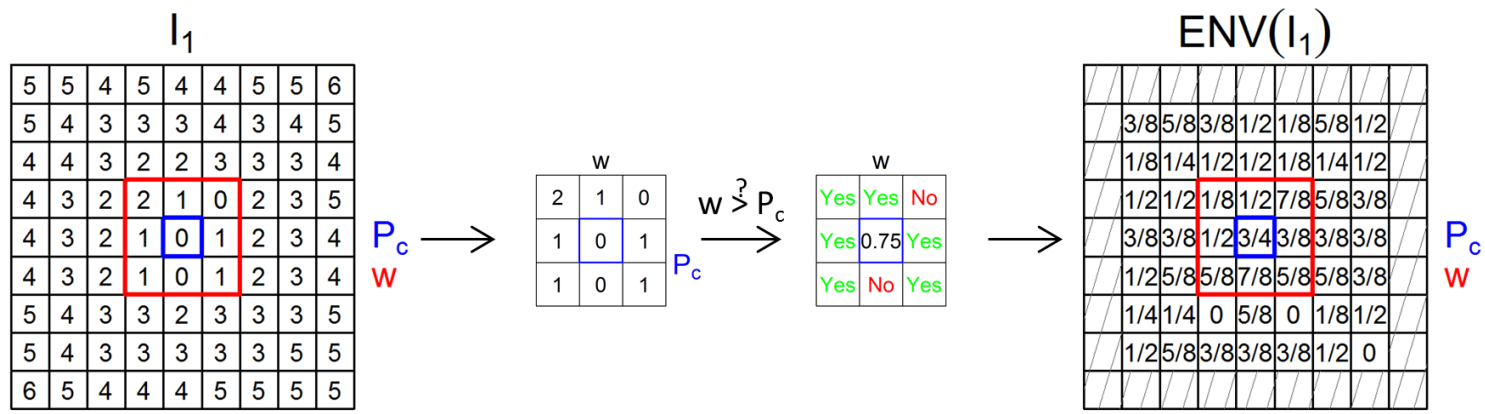

a)

Figure 5a. Analysis of the coefficient of variation via an "environment assessment" for a designed data set. The data are generated in the same way as in the previous analysis (see Fig. 3). Subfigure (a) illustrates the derivation of a single summary value for the central pixel $P_{\mathrm{c}}$ (blue) from the data of the surrounding environment $w$ (red). The example here investigates how many values within the environment are larger than the central value. This is repeated for all image pixels (except for boundary pixels), resulting in the rightmost picture.

Table 1. Overview on the 28 calculated principle components (PCs) regarding their accounted proportion of variance. In each column, the components show their specific standard deviation $(\sigma)$, proportion of variance (prop. of VAR) and cumulative proportion of variance (cum. prop.).

\begin{tabular}{lrrrrrrr}
\hline & PC1 & PC2 & PC3 & PC4 & PC5 & PC6 & PC7 \\
\hline$\sigma$ & 3.475 & 1.502 & 1.018 & 1.006 & 0.977 & 0.874 & 0.867 \\
prop. of VAR & 0.431 & 0.081 & 0.037 & 0.036 & 0.034 & 0.027 & 0.027 \\
cum. prop. & 0.431 & 0.512 & 0.549 & 0.585 & 0.619 & 0.646 & 0.673 \\
\hline & PC8 & PC9 & PC10 & PC11 & PC12 & PC13 & PC14 \\
\hline$\sigma$ & 0.843 & 0.834 & 0.792 & 0.754 & 0.746 & 0.730 & 0.713 \\
prop. of VAR & 0.025 & 0.025 & 0.022 & 0.020 & 0.020 & 0.019 & 0.018 \\
cum. prop. & 0.699 & 0.723 & 0.746 & 0.766 & 0.786 & 0.805 & 0.823 \\
\hline & PC15 & PC16 & PC17 & PC18 & PC19 & PC20 & PC21 \\
\hline$\sigma$ & 0.712 & 0.694 & 0.671 & 0.669 & 0.646 & 0.619 & 0.598 \\
prop. of VAR & 0.018 & 0.017 & 0.016 & 0.016 & 0.015 & 0.014 & 0.013 \\
cum. prop. & 0.841 & 0.858 & 0.875 & 0.891 & 0.905 & 0.919 & 0.932 \\
\hline & PC22 & PC23 & PC24 & PC25 & PC26 & PC27 & PC28 \\
\hline$\sigma$ & 0.589 & 0.575 & 0.555 & 0.535 & 0.525 & 0.483 & 0.357 \\
prop. of VAR & 0.012 & 0.012 & 0.011 & 0.010 & 0.010 & 0.008 & 0.005 \\
cum. prop. & 0.944 & 0.956 & 0.967 & 0.977 & 0.987 & 0.995 & 1.000 \\
\hline
\end{tabular}

values for forests. In this way, PC1 might be interpreted as related to similar dynamics in leaf area index (LAI; see Asner et al., 2003), and therefore the potential for water vapor and energy exchange between the land surface and the atmosphere. The high values for "mineral extraction" can be explained, as the single, relatively small area is surrounded by forests and partially replanted with smaller trees or shrubs during the observed time span.

When analyzing the component values of PC2 for the different geological classes, schist areas show distinct, different distributions compared to the other (mainly) sandstone areas. Schists with a high proportion of fractures are known for a high water drainage potential compared to the remaining sedimentary geology classes (see Chiang, 1971). The availability of water for transpiration and therefore the splitting of available energy into sensible and latent heat fluxes, resulting in different land surface temperatures, are thereby strongly affected. In this sense, PC2 can be interpreted as being related to bedrock information or coupled soil texture.

Even though land surface temperature is expected to depend on elevation and other terrain properties, no correlation for PC3 to PC5 (and higher) could be found with any other available observable land surface characteristic pattern and, in particular, to DEM related variables. For the Attert catchment, the elevation differences are moderate, and higher altitudes are related to the Schist areas (see Fig. 1). Thus, some 
Data

\begin{tabular}{|c|c|c|c|c|c|c|}
\hline \multicolumn{7}{|c|}{$\mathrm{I}_{1}$} \\
\hline 5 & & 4 & 4 & \begin{tabular}{|l|}
4 \\
\end{tabular} & \begin{tabular}{|l|l}
5 & 5 \\
\end{tabular} & \begin{tabular}{l|l}
5 & 6
\end{tabular} \\
\hline \begin{tabular}{|l|} 
\\
\end{tabular} & \begin{tabular}{|l|}
4 \\
\end{tabular} & \begin{tabular}{l|l}
3 \\
\end{tabular} & \begin{tabular}{|l|l|}
3 \\
\end{tabular} & \begin{tabular}{|l|}
4 \\
\end{tabular} & \begin{tabular}{|l|l|}
3 & 4 \\
\end{tabular} & \begin{tabular}{l|l}
45 \\
\end{tabular} \\
\hline \begin{tabular}{|l|}
4 \\
\end{tabular} & \begin{tabular}{|l|} 
\\
\end{tabular} & 3 & \begin{tabular}{l|l}
2 & 2 \\
\end{tabular} & \begin{tabular}{|l|l|} 
\\
\end{tabular} & \begin{tabular}{|l|l}
3 & 3 \\
\end{tabular} & \begin{tabular}{l|l}
3 & 4 \\
\end{tabular} \\
\hline \begin{tabular}{|l|}
4 \\
\end{tabular} & 3 & 22 & 21 & \begin{tabular}{|l|} 
\\
\end{tabular} & \begin{tabular}{|l|l}
2 & 3 \\
\end{tabular} & \begin{tabular}{l|l}
3 & 5 \\
\end{tabular} \\
\hline \begin{tabular}{|l|}
4 \\
\end{tabular} & 3 & 2 & 10 & \begin{tabular}{|l|} 
\\
\end{tabular} & \begin{tabular}{|l|l|}
2 \\
\end{tabular} & \begin{tabular}{|l|l}
3 & 4 \\
\end{tabular} \\
\hline \begin{tabular}{|l|} 
\\
\end{tabular} & 3 & 2 & 10 & 1 & \begin{tabular}{|l|l}
2 & 3 \\
\end{tabular} & \begin{tabular}{l|l}
3 & 4 \\
\end{tabular} \\
\hline \begin{tabular}{|l|}
5 \\
\end{tabular} & 44 & 3 & \begin{tabular}{l|l}
3 & 2 \\
\end{tabular} & \begin{tabular}{|l|l|} 
\\
\end{tabular} & \begin{tabular}{|l|l}
3 & 3 \\
\end{tabular} & \begin{tabular}{l|l}
3 & 5 \\
\end{tabular} \\
\hline \begin{tabular}{|l|}
5 \\
\end{tabular} & \begin{tabular}{|l|} 
\\
\end{tabular} & 3 & \begin{tabular}{l|l}
3 & 3 \\
\end{tabular} & \begin{tabular}{|l|}
3 \\
\end{tabular} & \begin{tabular}{|l|l}
3 & 5 \\
\end{tabular} & \begin{tabular}{|l|l}
5 & 5 \\
\end{tabular} \\
\hline & & & & & & \\
\hline
\end{tabular}<smiles>C[AlH]</smiles>

Environments ">"

$\operatorname{ENV}\left(\mathrm{I}_{1}\right)$

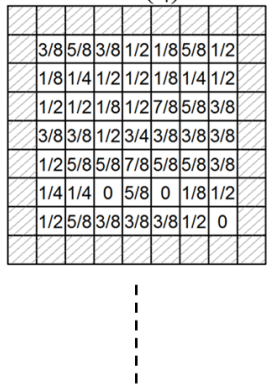

Environments "="

$\operatorname{ENV}\left(\mathrm{I}_{1}\right)$

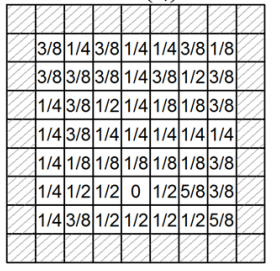

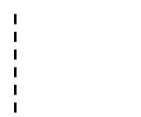

Environments "<"

$\operatorname{ENV}\left(\mathrm{I}_{1}\right)$

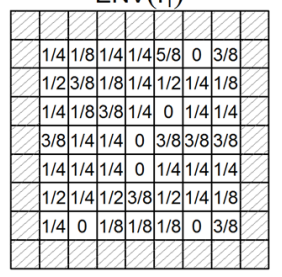
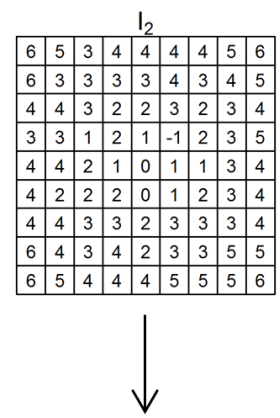

$\operatorname{ENV}\left(\mathrm{I}_{2}\right)$

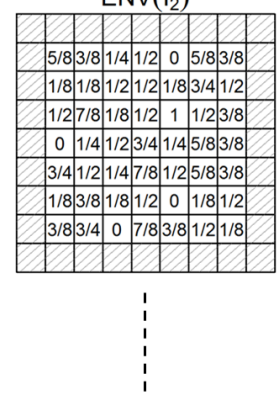

$\mathrm{ENV}\left(\mathrm{I}_{2}\right)$

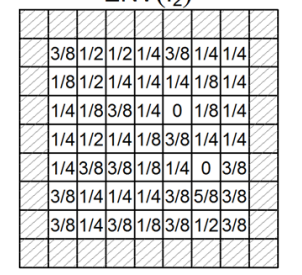

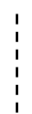

$\operatorname{ENV}\left(I_{2}\right)$

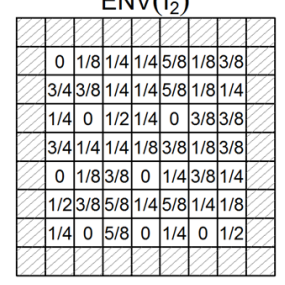

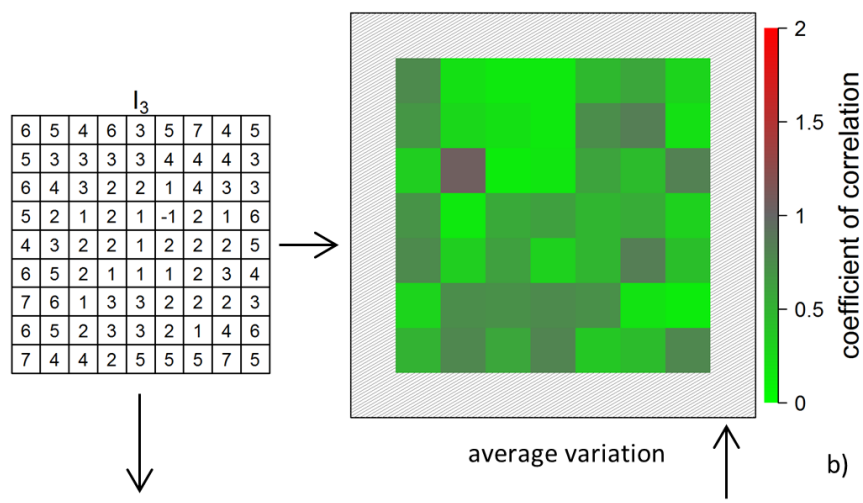
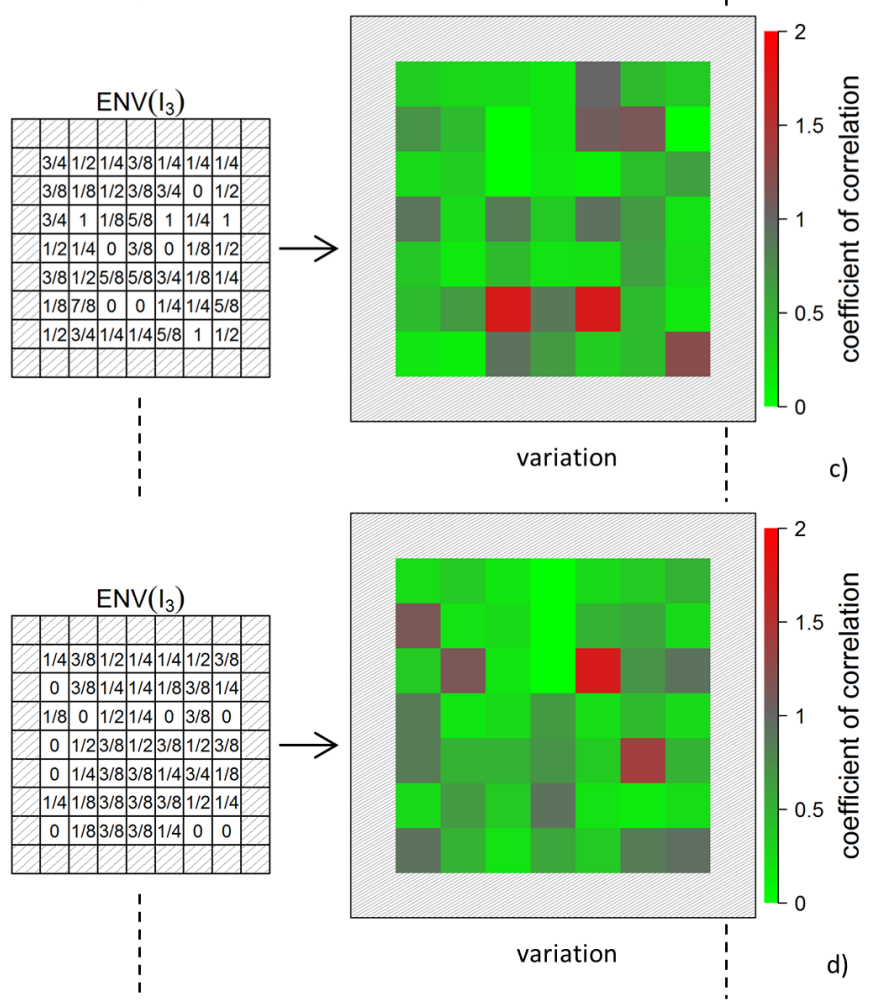

$\operatorname{ENV}\left(I_{3}\right)$

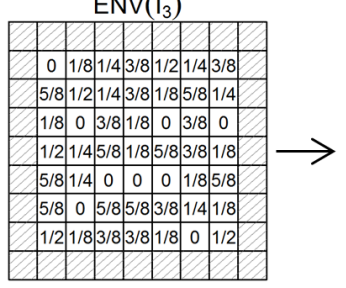

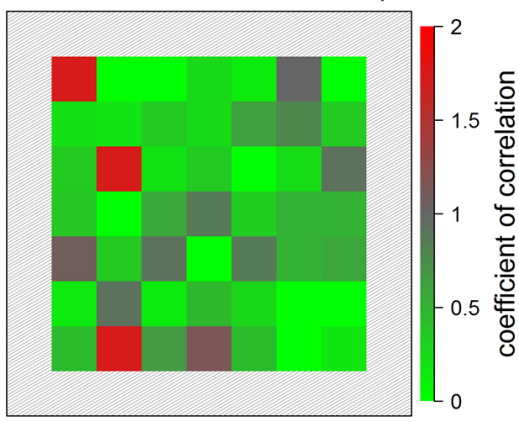

variation c)

d)

要

e)

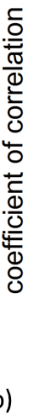

Figure 5b. Subfigures (b-e) illustrate the procedure from data set (b; left) to the environment measures (c-e; left), to the coefficients of variation for different environments (c-e; right) and to the final describing average pattern (b; right). 
Table 2. Loadings of the first five components (rows) to reproduce the LST time series (columns). The weights differ largely between the time steps. The lowest coefficient of variation for the loadings is calculated for PC1 (0.195); the highest value for PC2 (136.996). PC3, PC4 and PC5 have coefficients of variation of 80.131, 21.914 and 14.193.

\begin{tabular}{|c|c|c|c|c|c|c|c|}
\hline Loading of & 25 Feb 2001 & 23 Sep 2001 & 15 Feb 2003 & 21 Mar 2003 & 3 Aug 2003 & 15 Apr 2004 & 17 May 2004 \\
\hline PC1 & -0.055 & -0.056 & -0.044 & -0.054 & -0.052 & -0.038 & -0.048 \\
\hline $\mathrm{PC} 2$ & -0.050 & -0.038 & -0.099 & 0.012 & 0.026 & 0.054 & 0.023 \\
\hline PC3 & 0.045 & 0.006 & 0.042 & 0.041 & -0.043 & 0.099 & 0.057 \\
\hline PC4 & -0.066 & -0.072 & -0.013 & -0.054 & -0.055 & 0.009 & 0.029 \\
\hline \multirow[t]{2}{*}{ PC5 } & 0.059 & 0.000 & 0.075 & 0.016 & -0.018 & -0.028 & -0.098 \\
\hline & 24 May 2004 & 27 May 2005 & 12 Sep 2006 & 1 May 2007 & 15 Jul 2008 & $24 \mathrm{Jul} 2008$ & 26 Sep 2008 \\
\hline PC1 & -0.056 & -0.043 & -0.054 & -0.049 & -0.061 & -0.053 & -0.055 \\
\hline $\mathrm{PC} 2$ & 0.002 & -0.015 & 0.019 & 0.045 & -0.025 & -0.024 & 0.004 \\
\hline PC3 & 0.038 & 0.014 & -0.022 & -0.024 & -0.036 & -0.048 & -0.022 \\
\hline PC4 & 0.008 & 0.041 & -0.063 & 0.006 & 0.028 & 0.014 & -0.070 \\
\hline \multirow[t]{2}{*}{ PC5 } & -0.103 & -0.085 & -0.026 & -0.016 & -0.011 & -0.001 & 0.004 \\
\hline & 21 Mar 2009 & 20 Apr 2009 & 22 May 2009 & 23 Jun 2009 & 2 Jul 2009 & 27 Jul 2009 & 16 Apr 2010 \\
\hline PC1 & -0.059 & -0.038 & -0.050 & -0.043 & -0.042 & -0.049 & -0.034 \\
\hline PC2 & 0.026 & 0.026 & -0.041 & -0.028 & -0.037 & -0.033 & 0.098 \\
\hline PC3 & -0.004 & 0.010 & 0.007 & -0.067 & -0.052 & -0.022 & 0.010 \\
\hline $\mathrm{PC} 4$ & -0.011 & 0.091 & 0.061 & 0.078 & 0.112 & 0.008 & 0.020 \\
\hline \multirow[t]{2}{*}{ PC5 } & 0.042 & 0.075 & 0.007 & 0.049 & 0.000 & -0.006 & 0.104 \\
\hline & 23 Apr 2010 & 23 Sep 2010 & 19 Apr 2011 & 30 May 2011 & 6 Nov 2011 & 27 Mar 2012 & 14 May 2012 \\
\hline PC1 & -0.037 & -0.034 & -0.059 & -0.059 & -0.028 & -0.032 & -0.048 \\
\hline $\mathrm{PC} 2$ & 0.070 & 0.057 & -0.024 & -0.003 & -0.117 & 0.066 & 0.017 \\
\hline PC3 & 0.056 & -0.128 & -0.035 & -0.026 & 0.069 & 0.038 & 0.013 \\
\hline PC4 & 0.027 & -0.061 & 0.031 & -0.041 & -0.025 & -0.010 & 0.044 \\
\hline PC5 & 0.022 & 0.010 & -0.014 & -0.043 & 0.038 & 0.058 & -0.013 \\
\hline
\end{tabular}

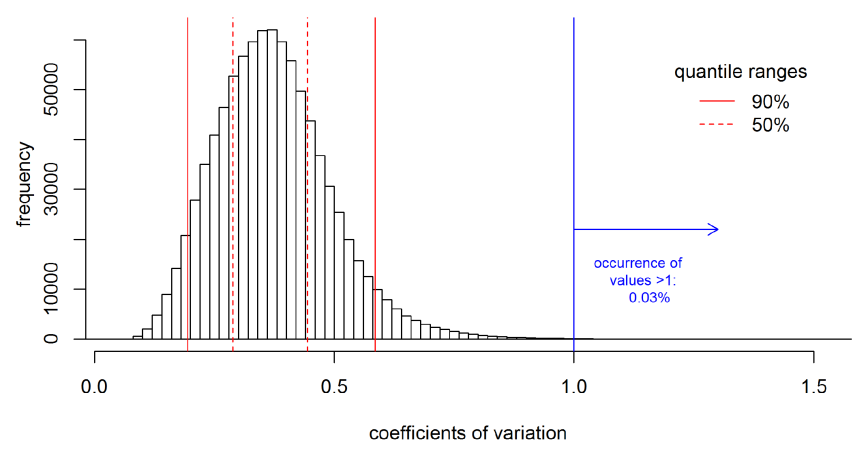

Figure 6. Coefficient of variation for the LST time series data. The median coefficient of variation is 0.34 , the mean value 0.35 . In all, $90 \%$ of the calculated values are within the range of 0.19 and 0.55 (red lines), $50 \%$ are within the range of 0.27 and 0.42 (red dashes) and $0.03 \%$ of the values are larger than 1 (blue arrow).

part of a possible elevation effect might be "hidden" in PC2 already. However, for other more mountainous areas, possible relationships might be more pronounced and should be considered and analyzed in detail.
In addition to the component values, PCA also provides information on the weight of each component within each single time step through calculation of the specific loadings. Table 2 illustrates the first five components and their loadings for the analyzed data set. While some dependencies of the sign, mean and standard deviation of the loadings with meteorological or hydrological conditions or states in the Attert catchment are expected, here, only the differences in the loadings at individual dates are used to identify a limited number of images that are most distinct in their information content but that represent the wide range of LST dynamics over the considered time period. Based on the cumulative Euclidean distance of loadings within the LST time series, a number of 5 exemplary images are selected for further analysis (15 February 2003, 17 May 2004, 24 May 2004, 27 May 2005 and 27 March 2012).

\subsection{Behavioral measure}

In the following, the temporal dynamics of LST data are analyzed in terms of their "functional behavior" and, to classify the catchment into areas that show some similarity in this behavior (functional units). Similar to the analysis of pattern 


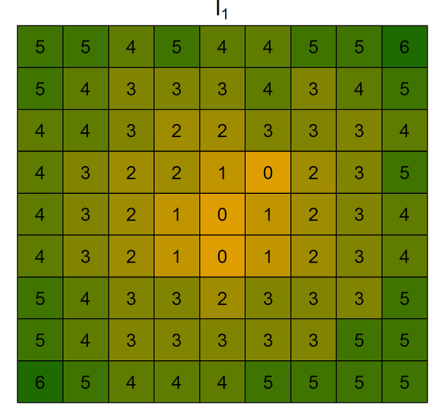

$\mathrm{PC} 1$

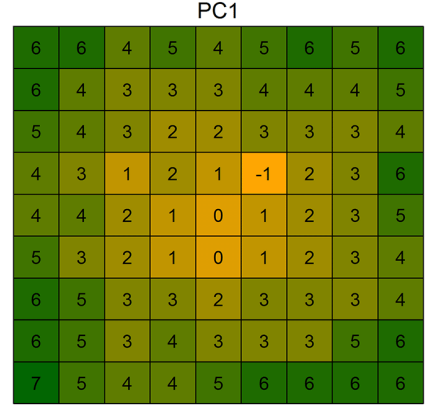

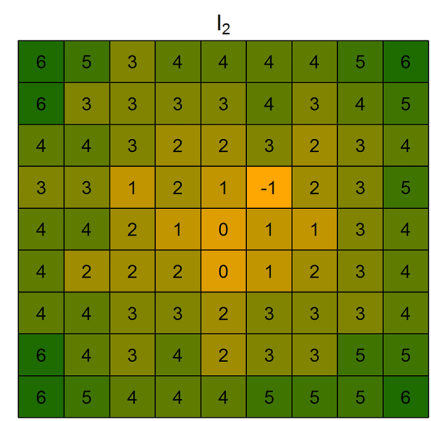

PC2

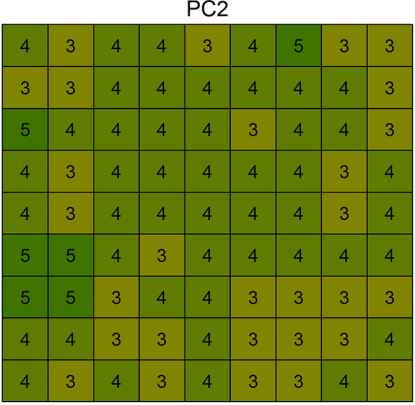

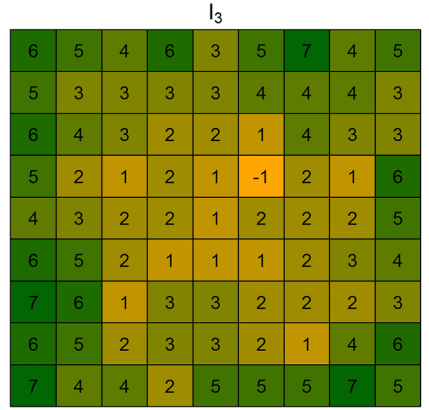

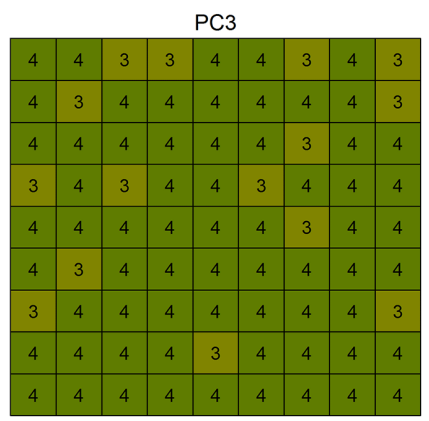

Figure 7. Principle component analysis for a designed data set. The data are the same as those for Fig. 5. The first row shows the pattern of the original data $\left(I_{1}-I_{3}\right)$, the second row shows the three resulting principle components (PC1-PC3). The PCs are scaled to the same numeric domain as the original data and colored alike (orange for low values; green for high values). PC1 shows the dominance of the concentric pattern, explaining $90.5 \%$ of overall variance of the data. PC2 and PC3 are more homogeneous and describe the noise of the construction of the data set.

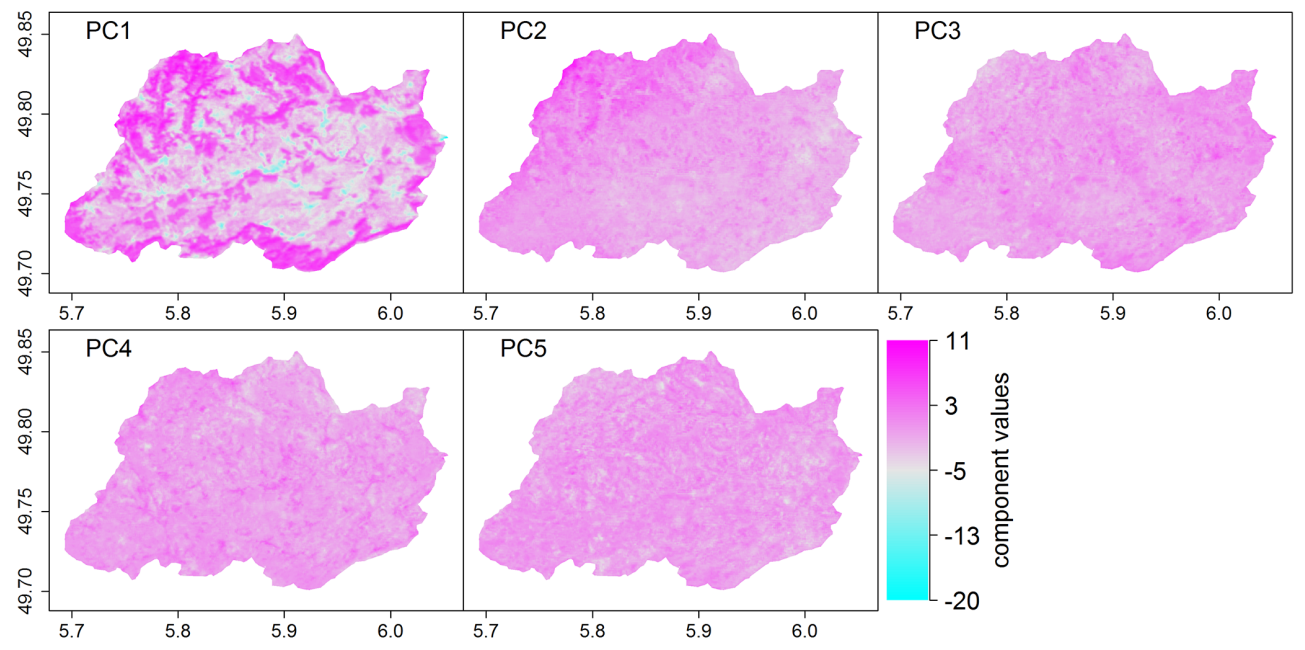

Figure 8. The first five components of the PCA for the LST time series data.

dynamics persistency, the vast data variability is transformed into simple information. Using the five most different images and therefore time steps (see Sect. 3.3), the data are binarized using an approach suggested by Hauhs and Lange (2008). The pixels of each image within the time step are separated into values larger than the median value of the image (1) or lower (0) (Fig. 11, left). The set of five binarized images can be aggregated into five-letter "words" (Hauhs and Lange, 2008) by concatenating these binary values (see the three-letter example in Fig. 11; right). The order of letters within the words represents the response of the land surface to differences in the water and energy balance for each pixel. These different land surface responses refer to differently behaving landscape units.

The transformation of the five LST images into behavioral words results in a (still manageable) number of $32\left(=2^{5}\right)$ classes throughout the catchment, as illustrated in Fig. 12. In some areas, functional behavior changes over short dis- 

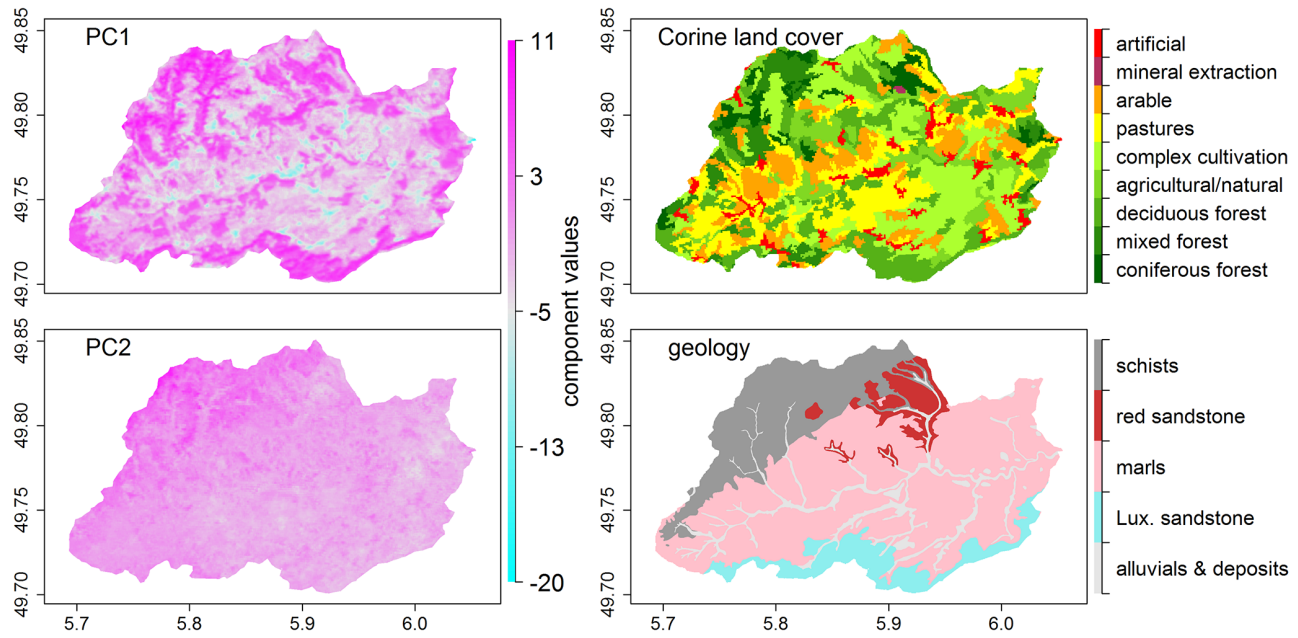

Figure 9. The first and second component of the PCA for the LST time series data (left) next to the patterns of the illustration of Corine land cover and geology data (right) of the Attert catchment.
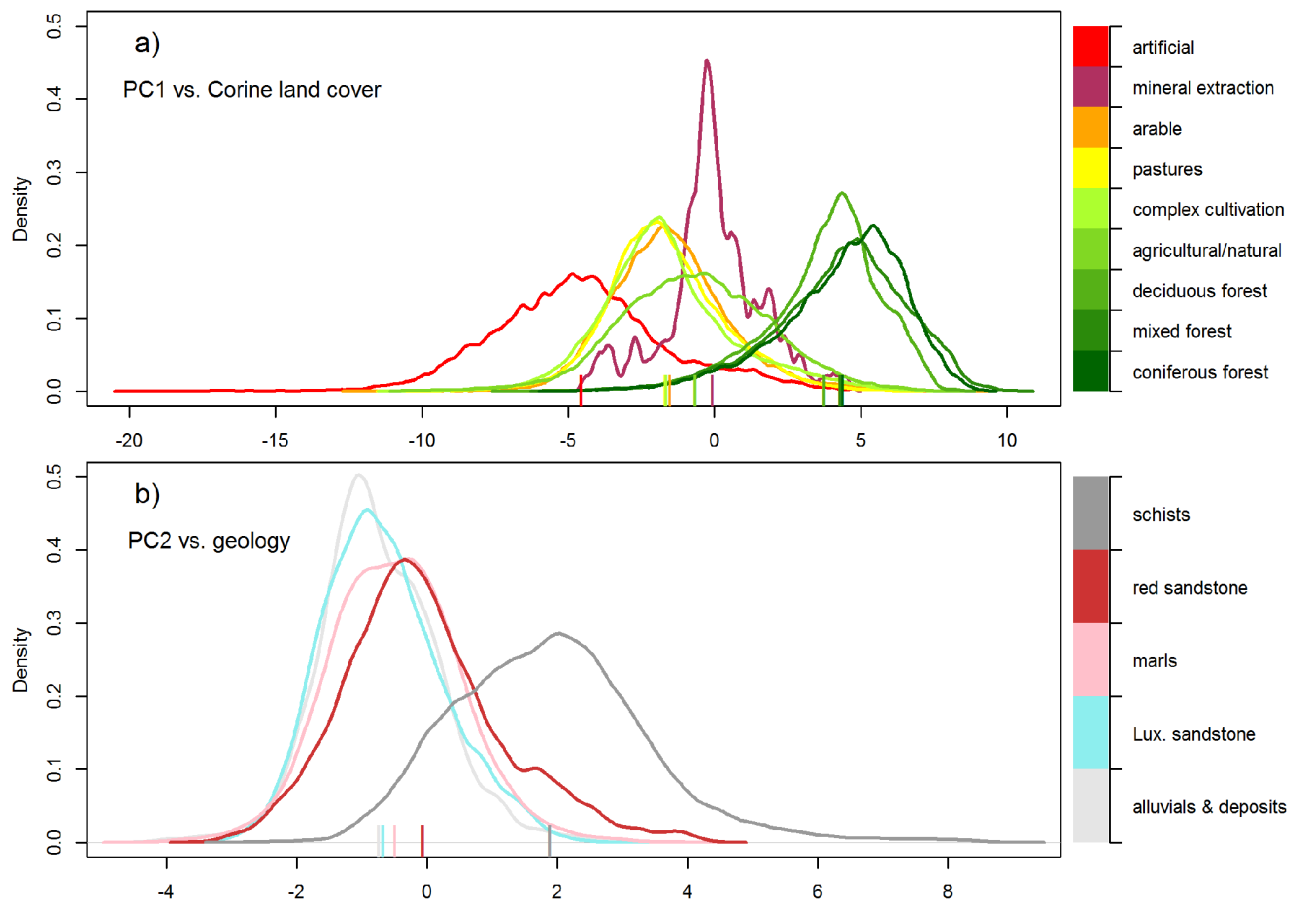

Figure 10. Comparison of component values and spatial information for the Attert catchment. The density distribution of the component values (PC1 in (a); PC2 in (b)) are shown for the different classes of the spatial data sets (Corine land cover in (a); geology in (b)). Mean values of the distributions are shown as vertical bars on the bottom line.

tances, indicating different response of the land surface towards radiation-driven conditions; other areas behave very similarly over larger spatial extent. These larger clusters are characterized by a constant behavior throughout the subset time series with short interruptions only (e.g., class "00010" only has one short "break" of length 1). Different binary words represent different land surface functioning and therefore allow the delineation of functional units (with a focus on the radiation-driven conditions) in the (Attert) catchment. Based on results from Figs. 9 and 12, larger units can be found within the forests (e.g., "00000", "10000", "00001"), main settlements or frequently bare soils ("11111") and large pastures ("11011" and "00100"). The heterogeneous areas are more related to periodical land cover changes and represent small-scale dominations of processes throughout the time series. 

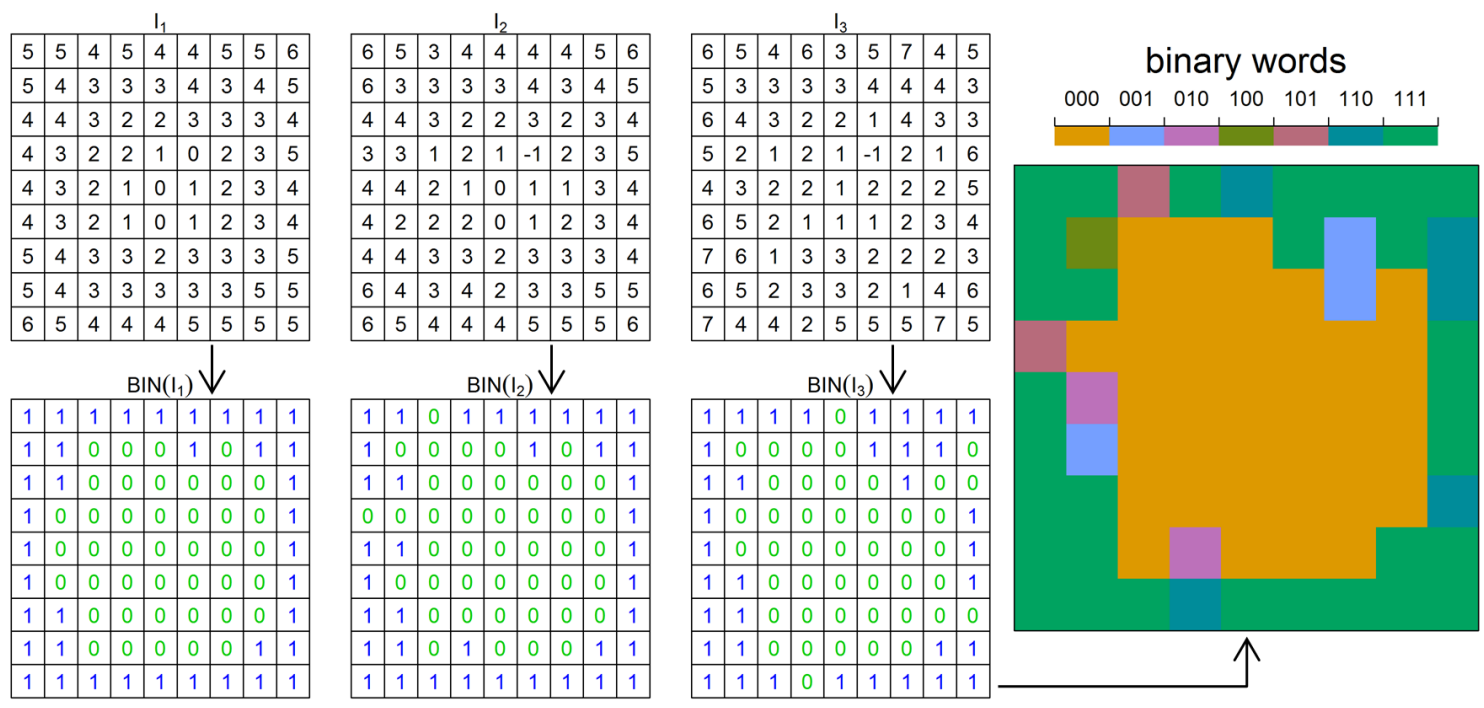

Figure 11. Construction of "binary word" classification for a designed data set. The data are the same as those for Fig. 5. On the left, the three images are binarized (BIN) from the upper to the lower panel. Values larger than the median are converted to 1 (blue), values lower are converted to 0 (green). The right panel shows the aggregated words for the three data sets. Not every possible occurrence of words is produced (maximum: $2^{3}=8$ ).

\section{Conclusions}

An alternative way of characterizing land surface functionality based on time series of thermal remote sensing images is introduced. Firstly, it is shown that the overall LST patterns of the time series are spatio-temporally persistent. Secondly, dominant patterns within the time series were extracted via PCA and could be related to physical ecological features, such as land use and geology. Based on these analyses, representative images from the time series were selected to express land surface functionality in terms of binary words and to classify land surface into different functional units that, again, could be related to existent land use patterns in the catchment. In contrast to the "classical" HRU delineation process - in which maps of land surface properties (DEM, land use, soil) that are often generalized, estimated, outdated or interpolated from sparse measures, are intersected, and hydrological similarity is assumed for these units - the derived principal components and values, as well as the classification with regards to binary words, both represent "real" and "onsite" catchment functional behavior with regards to LST and therefore to the water and energy balance at each location.

While ASTER data were used here, this approach is applicable to any other platform or sensor providing LST information (e.g., Landsat 8 data, $100 \mathrm{~m}$ resolution, TIR). Given the maximum spatial resolution of ca. $100 \mathrm{~m}$ in TIR remote sensing, any analysis concerning the size of functional similarity in the landscape is limited to that resolution. Aircraft-based TIR sensing might overcome this limitation, but it is still not routinely available yet. More global hence coarse patterns can be derived from geostationary satellites (e.g., Me- teosat) and might improve spatial representations of global standard data sets for climate modeling; e.g., the FAO (Food and Agriculture Organization of the United Nations) world soil map. By investigating the PCA results for different resolutions, it should also be possible to develop new statistical up and down scaling methods for model parameterizations. This approach is also limited by the number and seasonality of available (and almost cloud free) LST images. For the Attert catchment, a data set of 28 LST images was available for a period of ca. 12 years. Using the full data set, any significant land surface changes related to LST are implicitly contained and expressed in the derived principal components and their values, as well as in the derived classification of functional units using binary words. An analysis of historic Landsat images has shown that the land use changes in the Attert catchment have been minimal over the last 35 years, so crop rotation by farmers is the most dominant change over the seasons here. Given an average of not even three available images per year for this mid-latitude region (see Fig. 2), any application of this approach will have to balance between sufficient temporal coverage in order to capture the relevant LST dynamics of the landscape, and not covering too many externally driven changes in the procedure.

In order to analyze the number of images required, the PCA and "binary word" classification was repeated with down to just six subsequent images (given the minimum set of five images considered in Sects. 3.3 to 3.4). For all the subsets, results in terms of PCA, component values and classification were similar when compared to the full LST time series, indicating that already a much smaller time period and smaller number of images will be sufficient to capture land- 


\section{words}

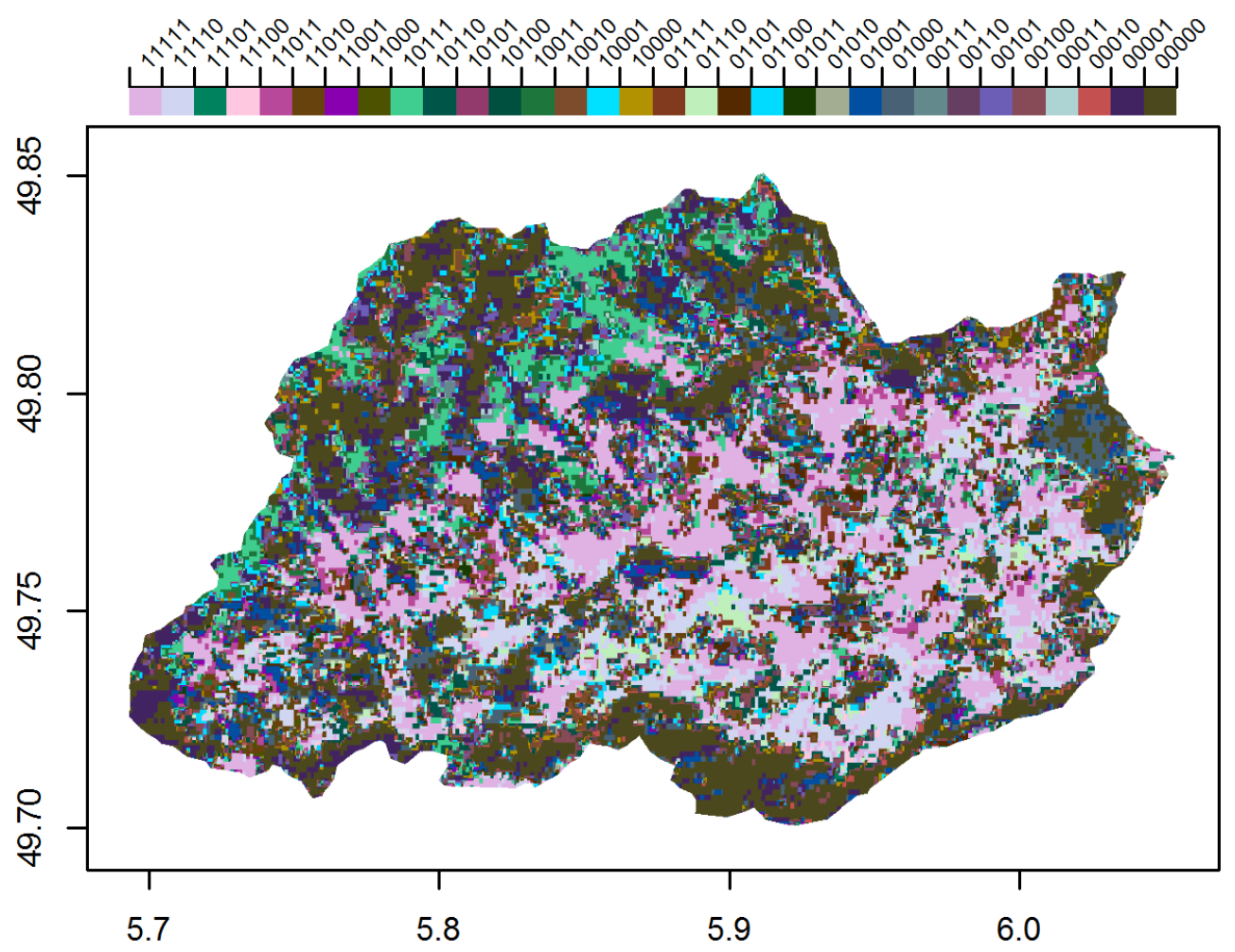

Figure 12. Behavioral classification of the subset LST time series data. The algorithm is producing $2^{5}=32$ classes of different frequency. The image shows the full bandwidth with classes named in the legend.

scape functioning with regards to LST. This might change with more complex landscapes. The application of digital numbers instead of extracted LST also showed almost identical results, so that a proper conversion to LST is, in our opinion, not fundamentally needed.

What are the additional benefits of the LST analysis presented here? The analysis of binary words, as presented in Sect. 3.4, provides a classification of the catchment into areas that behave similarly (with regards to the complex interactions of the water and energy balance, as expressed in LST) in terms of response to radiation-driven conditions. These units can either be used in an already-established HRU framework or can provide some guidance on the size of spatial discretization of the landscape in land surface modeling exercises. They might support effective observation and monitoring strategies under limited resources by providing distributed information of distinct behavior and hence might be used as decision support on the spatial distributions of field experiments. The strongest impact of the approach presented is expected when the derived component values from the PCA analysis will be incorporated into model parameter regionalization schemes (e.g., the multi-scale parameter regionalization (MPR) scheme presented by Samaniego et al.,
2010). Rather than providing nominal scaled data, the component values are continuous, pixel-based information representing the land surface functioning with regards to LST. Formulating the parameterization of land surface models by, e.g., transfer functions (see MPR) that are based on individual component values derived from PCA are expected to strongly improve the spatially explicit modeling of catchment water and energy fluxes. However, this hypothesis has still to be tested by comparing these different regionalization approaches within different models and catchments. By extending this analysis to further catchments under different terrain, climate and vegetation conditions, it is expected that a more general interpretation and understanding of principal components, component values and loadings and their occurrence and interrelation can be derived. The impact of elevation on LST will certainly be more dominant in mountainous areas, soil texture is supposed to show stronger signals in water-limited regions; information on variations within multi-level vegetation will appear in strongly natural and forested areas; and the association of PCA loadings with, e.g., meteorological measurements or indices (e.g., cumulative rainfall of the last 7 days) might allow further processes or states (such as interception storage) to be derived. 
Acknowledgements. We thank the German Research Foundation (DFG) for funding this research through the CAOS (Catchments as Organised, see CAOS reference below (marked) Systems) Research Unit (FOR 1598; grant no. SCHU1271/5-1). We also want to thank the LPDAAC (Land Processes Distributed Active Archive Center) for providing free ASTER data, as well as the editor and anonymous referees for their contributions to improve this article.

Edited by: H. Cloke

\section{References}

Arnold, J. G., Srinivasan, R., Muttiah, R. S., and Williams, J. R.: Large area hydrologic modeling and assessment Part I: Model development, J. Am. Water Resour. As., 34, 73-89, doi:10.1111/j.1752-1688.1998.tb05961.x, 1998.

Asner, G. P., Scurlock, J. M. O., and Hicke, J. A.: Global synthesis of leaf area index observations: implications for ecological and remote sensing studies, Global Ecol. Biogeogr., 12, 191-205, doi:10.1046/j.1466-822X.2003.00026.x, 2003.

Beven, K. J. and Kirkby, M. J.: A physically based, variable contributing area model of catchment hydrology, Hydrological Sciences Bulletin, 24, 43-69, doi:10.1080/02626667909491834, 1979.

Bolle, H.-J., Feddes, R. A., and Kalma, J. D. (Eds.): Exchange processes at the land surface for a range of space and time scales, in: Proceedings of Symposium J3.1, Joint Scientific Assembly of IAMAP and IAHS, Yokohama, Japan, 11-23 July 1993, 626 pp., 1993.

CAOS: CAOS - Catchments as Organised Systems, available at: http://www.caos-project.de (last access: 22 May 2014), 2014.

CESSLU: How to calculate reflectance and temperature using ASTER data, prepared by Abduwasit Ghulam, Center for Environmental Sciences at Saint Louis University, available at: http://www.gis.slu.edu/RS/ASTER_Reflectance_ Temperature_Calculation.php (last access: 22 May 2014), 2009.

Chiang, S. L.: A runoff potential rating table for soils, J. Hydrol., 13, 54-62, doi:10.1016/0022-1694(71)90200-9, 1971.

Crósta, A. P., De Souza Filho, C. R., Azevedo, F., and Brodie, C.: Targeting key alteration minerals in epithermal deposits in Patagonia, Argentina, using ASTER imagery and principal component analysis, Int. J. Remote Sens., 24, 4233-4240, doi:10.1080/0143116031000152291, 2003.

Denbo, D. W. and Allen, J. S.: Rotary empirical orthogonal function analysis of currents near the Oregon coast, J. Phys. Oceanogr, 14, 35-46, doi:10.1175/15200485(1984)014<0035:REOFAO>2.0.CO;2 1984.

EEA: CORINE Land Cover Project, published by Commission of the European Communities, available at: http://www.eea.europa. eu/publications/COR0-landcover (last access: 22 May 2014), 1995.

EEA: Environmental Terminology and Discovery Service (ETDS), published by European Environment Agency, available at: http://glossary.eea.europa.eu/terminology/concept_html?term= corine\%20land\%20cover (last access: 22 May 2014), 2014.
Eldeiry, A. and Garcia, L.: Comparison of ordinary kriging, regression kriging, and cokriging techniques to estimate soil salinity using LANDSAT images, J. Irrig. Drain. E.-ASCE, 136, 355364, doi:10.1061/(ASCE)IR.1943-4774.0000208, 2010.

Elder, T. and Strong, J.: The infrared transmission of atmospheric windows, J. Franklin I, 255, 189-208, doi:10.1016/00160032(53)90002-7, 1953.

EPA: Multi-Resolution Land Characteristics Consortium (MRLC), available at: http://www.epa.gov/mrlc/ (last access: 22 May 2014), 2007.

Farah, H. O. and Bastiaanssen, W. G. M.: Impact of spatial variations of land surface parameters on regional evaporation: a case study with remote sensing data, Hydrol. Process., 15, 15851607, doi:10.1002/hyp.159, 2001.

Farr, T. G., Rosen, P. A., Caro, E., Crippen, R., Dure, R., Hensley, S., Kobrick, M., Paller, M., Rodriguez, E., Roth, L., Seal, D., Shaffer, S., Shimada, J., Umland, J., Werner, M., Oskin, M., Burbank, D., and Alsdorf, D.: The shuttle radar topography mission, Rev. Geophys., 45, RG2004, doi:10.1029/2005RG000183, 2007.

Flügel, W. A.: Delineating Hydrological Response Units (HRUs) by GIS analysis for regional hydrological modelling using PRMS/MMS in the drainage basin of the River Bröl, Germany, Hydrol. Process., 9, 423-436, doi:10.1002/hyp.3360090313, 1995a.

Flügel, W. A.: Hydrological Response Units (HRUs) to preserve basin heterogeneity in hydrological modelling using PRMS/MMS - case study in the Bröl basin, Germany, in: Modelling and Management of Sustainable Basin-Scale Water Resource Systems, Boulder, Colorado, USA, 1-14 July 1995, 7987, 1995b.

Fujisada, H.: Design and performance of ASTER instrument, in: Advanced and Next-Generation Satellites, Proceedings of SPIE, Paris, France, 15 December 1995, 16-25, doi:10.1117/12.228565, 1995.

Hamlington, B. D., Leben, R. R., Nerem, R. S., Han, W., and Kim, K. Y.: Reconstructing sea level using cyclostationary empirical orthogonal functions, J. Geophys. Res.-Oceans, 1978-2012, 116, doi:10.1029/2011JC007529, 2011.

Hauhs, M. and Lange, H.: Classification of runoff in headwater catchments: a physical problem?, Geography Compass, 2, 235254, doi:10.1111/j.1749-8198.2007.00075.x, 2008.

Hirschmüller, H., Innocent, P. R., and Garibaldi, J.: Real-time correlation-based stereo vision with reduced border errors, Int. J. Comput. Vision, 47, 229-246, doi:10.1023/A:1014554110407, 2002.

Hook, S. J., Vaughan, R. G., Tonooka, H., and Schladow, S. G.: Absolute radiometric in-flight validation of mid infrared and thermal infrared data from ASTER and MODIS on the terra spacecraft using the Lake Tahoe, CA/NV, USA, automated validation site, IEEE T. Geosci. Remote, 45, 1798-1807, doi:10.1109/TGRS.2007.894564, 2007.

Kheir, R. B., Greve, M. H., Bøcher, P. K., Greve, M. B., Larsen, R., and McCloy, K.: Predictive mapping of soil organic carbon in wet cultivated lands using classification-tree based models: the case study of Denmark, J. Environ. Manage., 91, 1150-1160, doi:10.1016/j.jenvman.2010.01.001, 2010.

Ladoni, M., Bahrami, H. A., Alavipanah, S. K., and Noroozi, A. A.: Estimating soil organic carbon from soil reflectance: a re- 
view, precision agriculture, 11, 82-100, doi:10.1007/s11119009-9123-3, 2010.

Lagacherie, P., Bailly, J. S., Monestiez, P., and Gomez, C.: Using scattered hyperspectral imagery data to map the soil properties of a region, Eur. J. Soil Sci., 63, 110-119, doi:10.1111/j.13652389.2011.01409.x, 2012.

Lorenz, E. N.: Empirical orthogonal functions and statistical weather prediction, Scientific Report No. 1, Statistical Forecasting Project, Department of Meteorology, MIT, 49 pp., 1956.

Moore, F., Rastmanesh, F., Asadi, H., and Modabberi, S.: Mapping mineralogical alteration using principal-component analysis and matched filter processing in the Takab area, north-west Iran, from ASTER data, Int. J. Remote Sens., 29, 2851-2867, doi:10.1080/01431160701418989, 2008.

Moran, M. S.: Thermal infrared measurement as an indicator of plant ecosystem health, in: Thermal Remote Sensing in Land Surface Processes, edited by: Quattrochi, D. A. and Luvall, J., CRC Press, Boca Raton, Florida, USA, 257-282, doi:10.1201/9780203502174-c9, 2004.

Mulder, V. L., de Bruin, S., Schaepman, M. E., and Mayr, T. R.: The use of remote sensing in soil and terrain mapping - a review, Geoderma, 162, 1-19, doi:10.1016/j.geoderma.2010.12.018, 2011.

NASA: Shuttle Radar Topography Mission, available at: http:// www2.jpl.nasa.gov/srtm (last access: 22 May 2014), 2009.

Neumann, L. N., Western, A. W., and Argent, R. M.: The sensitivity of simulated flow and water quality response to spatial heterogeneity on a hillslope in the Tarrawarra catchment, Australia, Hydrol Proc., 24, 76-86, doi:10.1002/hyp.7486, 2010.

Pomeroy, J. W., Gray, D. M., Brown, T., Hedstrom, N. R., Quinton, W. L., Granger, R. J., and Carey, S. K.: The cold regions hydrological model: a platform for basing process representation and model structure on physical evidence, Hydrol. Process., 21, 2650-2667, doi:10.1002/hyp.6787, 2007.

Richards, J. A. and Jia, X.: The principal components transformation, in: Remote Sensing Digital Image Analysis: an Introduction, 4th Edn., Springer, Berlin, Germany, 133-148, 2006.

Samaniego, L., Kumar, R., and Attinger, S.: Multiscale parameter regionalization of a grid-based hydrologic model at the mesoscale, Water Resour. Res., 46, W05523, doi:10.1029/2008WR007327, 2010.
Serbin, G., Daughtry, C. S. T., Hunt, E. R., Jr., Reeves III, J. B., and Brown, D. J.: Effects of soil composition and mineralogy on remote sensing of crop residue cover, Remote Sens. Environ., 113, 224-238, doi:10.1016/j.rse.2008.09.004, 2009a.

Serbin, G., Hunt, E. R., Jr., Daughtry, C. S. T., McCarty, G. W., and Doraiswamy, P. C.: An improved ASTER index for remote sensing of crop residue, Remote Sensing, 1, 971-991, doi:10.3390/rs1040971, 2009b.

SGL: Carte Géologique du Luxembourg, Feuille No. 7, Redange, 1:25 000, R. Colpach, Service Géologique du Luxembourg, Luxembourg, 2003.

Srinivasan, R., Ramanarayanan, T. S., Arnold, J. G., and Bednarz, S. T.: Large area hydrologic modeling and assessment, Part II: Model application, J. Am. Water Resour. As., 34, 91-101, doi:10.1111/j.1752-1688.1998.tb05962.x, 1998.

Steenpass, C., Vanderborght, J., Herbst, M., Simunek, J., and Vereecken, H.: Estimating soil hydraulic properties from infrared measurements of soil surface temperatures and TDR data, Vadose Zone J., 9, 910-924, doi:10.2136/vzj2009.0176, 2010.

Summers, D., Lewis, M., Ostendorf, B., and Chittleborough, D. Unmixing of soil types and estimation of soil exposure with simulated hyperspectral imagery, Int. J. Remote Sens., 32, $6507-$ 6526, doi:10.1080/01431161.2010.512931, 2011.

Taiz, L. and Zeiger, E.: Plant Physiology, 5th Edn., Sinauer Associates, Sunderland, Massachusetts, USA, 782 pp., 2010.

Zehe, E., Ehret, U., Pfister, L., Blume, T., Schröder, B., Westhoff, M., Jackisch, C., Schymanski, S. J., Weiler, M., Schulz, K., Allroggen, N., Tronicke, J., Dietrich, P., Scherer, U., Eccard, J., Wulfmeyer, V., and Kleidon, A.: HESS Opinions: Functional units: a novel framework to explore the link between spatial organization and hydrological functioning of intermediate scale catchments, Hydrol. Earth Syst. Sci. Discuss., 11, 3249-3313, doi:10.5194/hessd-11-3249-2014, 2014. 